\title{
Evaluación de dos métodos para la separación de RNA mensajero de Plasmodium falciparum
}

\author{
Heidy Y. Guerrero ${ }^{1}$, Maria Orfa Rojas ${ }^{2}$, Moisés Wasserman ${ }^{2}$
}

\begin{abstract}
Resumen
En muchos casos, el estudio de la regulación de la expresión de genes específicos, requiere el aislamiento de su RNA mensajero (mRNA) a partir del RNA total presente en la célula. Con el fin de garantizar la presencia de secuencias que se expresan en baja abundancia, es indispensable obtener preparaciones de mRNA que sean representativas de la población de mensajeros del organismo en estudio. En este trabajo se evaluó el rendimiento del mRNA de Plasmodium falciparum obtenido por dos métodos: cromatografía de afinidad en columnas de oligo dT celulosa y captura del mRNA por hibridización en solución con un primer oligo dT. Con los dos métodos, se obtuvieron rendimientos similares en un rango entre 0,7 y $1,1 \%$ con respecto al RNA total de partida. El tamaño del cDNA sintetizado a partir de mensajeros separados por cromatografía fue de 0,4 a $4 \mathrm{~Kb}$, mientras que los provenientes del método de captu$\mathrm{ra}$, permitieron un rango entre 0,4 y $8 \mathrm{~Kb}$. Este hecho sugiere las mejores posibilidades que ofrece el método de captura para obtener poblaciones de mensajeros con mayores tamaños, si se compara con el método tradicional. La presencia de clones con genes de copia única como son los de tubulina, actina II, miosina, calmodulina, glucosa fosfato-isomerasa y glucosa-fosfato-deshidrogenasa, en genotecas de cDNA, permiten inferir una buena representatividad de las secuencias expresadas en la preparación de mRNA.
\end{abstract}

\section{Evaluation of two methods for the separation of Plasmodium falciparum messenger RNA.}

The study of gene expression regulation often requires the isolation of mRNA from the total RNA present in the cell. To guarantee the presence of sequences which are not expressed in abundance, it is necessary to obtain mRNA preparations which fully represent the messenger population of the organisms under study. In this work, Plasmodium falciparum mRNA purification efficiency, obtained by two methods, is evaluated: affinity chromatography using oligo dT cellulose columns and mRNA capture by solution hybridisation with an oligo dT primer. Similar mRNA amounts were obtained by the two methods and purification efficiency was between 0.7 and $1.1 \%$ of the total RNA used initially. The size of the cDNA synthesised by the affinity chromatography method $(0.4-4 \mathrm{~Kb})$ and by the capture method $(0.4-8 \mathrm{~Kb})$, shows that

1 Grupo de Bioquímica, Instituto Nacional de Salud, Santa Fe de Bogotá, Colombia.

2 Grupo de Bioquímica, Instituto Nacional de Salud y Facultad de Ciencias de la Universidad Nacional de Colombia, Santa Fe de Bogotá, Colombia.

Recibido para su publícación: enero 30 de 1998 
the second method produced longer mRNAs than the first one. The finding of one copy gene clones such as tubulin, actin II, myosin, calmodulin, glucose phosphate isomerase and glucose phosphate dehydrogenase, in cDNA gene libraries, allows us to infer a good expressed sequence representativity in mRNA preparation.

El estudio de la expresión de la información genética en eucariotes superiores depende en gran parte de las técnicas de detección y aislamiento de ARN mensajero (mARN) de genes específicos. Una de las mayores dificultades que se han encontrado en su aislamiento, ha sido obtener la pequeña fracción de ARN que constituye un mensajero específico a partir de la población de ARN total presente en dichas preparaciones (1).

De la totalidad del ARN de una célula eucariótica, $80-85 \%$ corresponde a rARN. La mayor parte del ARN restante, $15-20 \%$, está constituido por una variedad de especies de ARN de tamaño molecular pequeño, como son el ARN de transferencia (tARN) y el ARN nuclear pequeño. Estas especies de ARN se pueden aislar con base en su tamaño por electroforesis, centrifugación en gradientes de densidad o cromatografía líquida de alta resolución. Por el contrario, el mARN que constituye entre el 1 y $5 \%$ del ARN celular total, es heterogéneo en secuencia y tamaño (puede ir desde unos pocos cientos de bases hasta muchos kilobases en longitud), lo cual hace difícil separarlo del conjunto de ARN celular (2).

Entre las técnicas que se han desarrollado para el aislamiento y detección de mARN de células animales, muchas se basan en los estudios de cinética de marcación radiactiva de ARN polisomal y otras utilizan diferencias en sus tamaños moleculares. Existen metodologías que han probado ser de gran utilidad, al explotar algunas de las propiedades específicas del mARN (1).

En células eucarióticas, el mARN difiere de otras especies de ARN, en que contiene en su extremo 3', una extensión relativamente grande de 200 a 300 residuos de adenina, en una secuencia conocida como poli $\mathrm{A}^{+}$. Hasta el momento se desconoce el papel exacto de esta región rica en poli $\mathrm{A}^{+}$en el metabolismo del mARN, pero se ha sugerido que está involucrada en el transporte de mARN desde el núcleo celular al citoplasma donde ocurre la síntesis proteica y en la estabilidad del mensajero (3).

Dado que la extensión de residuos poli $\mathrm{A}^{+}$es suficientemente grande, se puede hibridizar con oligo dT celulosa, para separarlo del conjunto de ARN celular por cromatografía de afinidad. La población heterogénea de moléculas resultantes codifica colectivamente todas las proteínas sintetizadas por la célula (1).

La cromatografía de afinidad en columnas de oligo dT celulosa ha demostrado ser una técnica conveniente para la purificación parcial de cantidades apreciables de $\mathrm{mARN}$ poli $\mathrm{A}^{+}$ funcional y presenta las siguientes ventajas:

- El oligodeoxinucleótido es químicamente estable y la matriz se puede usar repetidamente después de un tratamiento con álcali.

- Estas columnas tienen una capacidad relativamente alta y se pueden usar para aislar varios microgramos de mARN poli $A^{+}(160-$ $200 \mathrm{mg}$ ) a partir de ARN polisomal crudo, saturando un gramo de resina oligo dT celulosa. Aproximadamente $1 \%$ del ARN que se pasa por la columna, se recupera como ARN poli $A$.

- El proceso se puede hacer a temperatura ambiente, con las precauciones necesarias para eliminar contaminación con nucleasas.

Se ha demostrado que los productos aislados bajo estas condiciones retienen su actividad funcional y se pueden aplicar convenientemente a gradientes de sacarosa para una mayor purificación (1).

Esta técnica ha sufrido algunas modificaciones en las cuales se sustituye la matriz de oligo dT celulosa por sephadex poli U. Esta matriz tiene una extensión más larga de nucleótidos y una velocidad de flujo mejor que las de oligo dT celulosa (4). 
En cualquier caso, en estas cromatografías es crítico tener soluciones libres de ARNasas, cuando se hace la selección de poli $\mathrm{A}^{+}$. Esto es debido a que en la mayoría de aplicaciones se necesita intacto el extremo 5' del mARN. Por consiguiente, no se puede tolerar ninguna ruptura entre los extremos 5' y 3' del mARN. Un segundo aspecto crítico es que el tamaño de la columna sea proporcional a la cantidad de ARN que va a ser seleccionado. El tamaño de la columna determina el volumen en el cual se eluye el ARN poli $\mathrm{A}^{+}(5)$.

Recientemente se han desarrollado otras tecnologías para obtener mARN a partir de ARN total, que eliminan la necesidad de usar columnas de oligo dT celulosa y sus problemas asociados. La fracción de mARN poly $\mathrm{A}^{+}$se puede aislar libre de todos los otros ácidos nucleicos contaminantes, de modo que es aceptable para todas las aplicaciones de biología molecular, incluyendo traducción in vitro y síntesis de cADN. El sistema usa un iniciador (primer) oligo dT biotinilado para hibridizar en solución a la región $3^{\prime}$ poly $\mathrm{A}^{+}$presente en las especies de mARN eucarióticas maduras. Los híbridos se capturan usando estreptavidina acoplada a partículas magnéticas. Se ha sugerido que mediante este procedimiento se obtienen mensajeros intactos de gran longitud (6).

En este estudio se compararon el rendimiento y la calidad del mARN de Plasmodium falciparum obtenido por dos métodos de separación: cromatografía de afinidad en columnas de oligo dT celulosa y captura por hibridación en solución del mARN con un primer oligo dT. La calidad del mARN obtenido se evaluó espectrofotométricamente para los dos tipos de preparaciones y por la búsqueda de la representatividad de una población de mensajeros en una genoteca de CADN construida a partir del mARN obtenido por el método de cromatografía de afinidad en columnas de oligo dT celulosa.

\section{Materiales y métodos}

\section{Extracción de ARN total}

Para la extracción de ARN total se siguió un protocolo previamente estandarizado (7), basado en la extracción de ARN con sales de guanidina (que inhiben la acción de ARNasas) y su separación de ADN y proteínas a través de un colchón de cloruro de cesio. Este método inició con cultivos de parásitos en el estadío de trofozoitos maduros (36 horas) asincrónicos. Los parásitos se liberaron del eritrocito mediante lisis con saponina $0,15 \%$ en HBS (8). Se recolectaron por centrifugación a $5000 \mathrm{~g}, 10 \mathrm{~min}$, $4^{\circ} \mathrm{C}$ y se hicieron dos lavados con la misma solución.

Para extraer el ARN se partió de $2 \times 10^{9}$ parásitos, los cuales se lisaron en una solución $4 \mathrm{M}$ de isotiocianato de guanidina, $25 \mathrm{mM}$ de citrato de sodio $\mathrm{pH} 7,0,5 \%$ de sarcosilato de sodio y $0,1 \mathrm{M}$ de b mercaptoetanol. La suspensión se homogeneizó y se extrajo con una mezcla fenol:cloroformo:alcohol isoamílico $(25: 24: 1 \mathrm{~V} /$ V). La fase acuosa $(3,5 \mathrm{~mL})$ se adicionó sobre la superficie de un colchón de $5.7 \mathrm{M}$ de cloruro de cesio y $10 \mathrm{mM}$ EDTA $(1,5 \mathrm{~mL})$ y el ARN se sedimentó por centrifugación a $120.000 \mathrm{~g}$ (RPS65T swing rotor, Hitachi) por 20 horas a $20^{\circ} \mathrm{C}$. El ARN se resuspendió en $10 \mathrm{mM}$ Tris $\mathrm{pH}$ 7,4, $5 \mathrm{mM}$ EDTA, 0,1\% SDS. Luego, se precipitó con 2,5 volúmenes de etanol y $0,3 \mathrm{M}$ de acetato de sodio. Después de la precipitación etanólica se hizo un lavado con $70 \%$ de isopropanol, se secó al vacío y se resuspendió en agua tratada con dietil pirocarbonato (libre de ARNasas) (7).

\section{Separación de ARN mensajero por croma- tografía de afinidad en columnas de oligo dT celulosa}

Para este protocolo, se usaron columnas de oligo dT celulosa preempacadas (Marca BRL), cuya capacidad de unión es el equivalente a 6 unidades de absorvancia a $260 \mathrm{~nm}$, es decir, aproximadamente $200 \mathrm{mg}$ de mARN.

Antes de cargar la muestra en la columna, se hizo un lavado con $0,1 \mathrm{M} \mathrm{NaOH}$ y se equilibró con buffer de unión (10 mM Tris- $\mathrm{HCl}$ pH 7,5, 1 mM EDTA, $0,3 \mathrm{M} \mathrm{NaCl}$ y $0,1 \%$ SDS). EI ARN total resuspendido en la misma solución, se denaturó a $70^{\circ} \mathrm{C}$ por 5 minutos, se cargó en la columna y se lavó con buffer de unión para eluir otras especies de ARN. El mARN unido a la 
columna, se eluyó con buffer de baja fuerza iónica (10 mM Tris-HCl pH 7,5, 1 mM EDTA y $0,1 \%$ SDS). La columna se reequilibró y se volvió a pasar el mARN eluido previamente denaturado, para su mayor purificación. Finalmente, el mARN eluido se precipitó con dos volúmenes de etanol y $0,3 \mathrm{M}$ de $\mathrm{NaCl}$; se lavó con etanol al $70 \%$, se secó y resuspendió en agua tratada con dietil pirocarbonato (1).

\section{Aislamiento de mARN por captura en solución}

Mediante este sistema, se separó mARN a partir de $1 \mathrm{mg}$ de ARN total, el cual se denaturó a $65^{\circ} \mathrm{C}, 10 \mathrm{~min}$ y se hibridizó en solución con un primer oligo dT biotinilado en buffer $0,5 \times \mathrm{SSC}$ a temperatura ambiente. Esta mezcla de hibridización se hizo reaccionar con partículas paramagnéticas acopladas a estreptavidina en buffer $0.5 \times S S C$ a temperatura ambiente. Los híbridos se capturaron usando un soporte imantado, se eliminó el sobrenadante y se hicieron lavados con alta astringencia para eliminar completamente el ARN no mensajero. Finalmente, el mARN se eluyó de la fase sólida con agua tratada con dietil-pirocarbonato y se precipitó con un volumen de isopropanol en presencia de $0,3 \mathrm{M}$ de acetato de sodio. Se lavó con $70 \%$ de etanol, se secó y resuspendió en agua (6).

\section{Evaluación del rendimiento y calidad del} mRNA obtenido por cada uno de los métodos

\section{Rendimiento}

Se estimó la concentración del ARN asumiendo que una solución de ARN de $40 \mathrm{mg} / \mathrm{mL}$ tiene una absorvancia de 1 a $260 \mathrm{~nm}$. El rendimiento del mARN obtenido, se calculó como un porcentaje de la cantidad de ARN total utilizado en el ensayo.

\section{Calidad}

Tanto la pureza como el tamaño del mARN son características importantes si se desea clonar el cADN y son esenciales para analizar la expresión de los genes que los codifican. Para estudios de expresión, se requiere un ARN completamente libre de ADN. Dicha pureza fue parcialmente evaluada por espectrofotometría a partir de la relación de absorbancia $A_{260} / A_{280}$ del ARN.

La calidad de las preparaciones de mARN obtenidas, también se evaluó de forma indirecta, mediante el análisis en geles de agarosa al $1 \%$, del tamaño de la población de cADN sintetizado y la búsqueda de la representatividad de la población de mensajeros del parásito, en genotecas de cADN. Los tamaños del cADN sintetizado tanto en la primera como en la segunda cadena, se confirmaron por autoradiografía (datos no mostrados) y el rastreo de los clones positivos se hizo por PCR como se describe más adelante.

Para que una genoteca sea representativa, debe contener como mínimo un clon de cADN de cada mARN de la célula y, por tanto, se debe determinar el número mínimo de clones que son requeridos para garantizar las secuencias de baja abundancia. P. falciparum tiene alrededor de 2.000 a 5.000 especies diferentes de mARN de las cuales los mARN de baja abundancia corresponden a $0,1 \%$ o menos. Para este caso, se ha determinado que el número mínimo de clones totales requeridos para construir una genoteca completa es 1,6 × $10^{4}(9)$. El objetivo final de una genoteca, por lo tanto, es poder expresar los fragmentos de cADN clonados y poder encontrar el mayor número de genes posibles.

Para construir la genoteca, se hizo síntesis de cADN (10) y clonación mediante el sistema superscript de BRL. Para la síntesis de cADN de cadena sencilla, se utilizó un primer oligo dT que hibridiza con el extremo poli $\mathrm{A}^{+}$del mARN, el cual está unido a un adaptador que contiene el sitio de restricción para la enzima Not 1 . En la reacción de síntesis, se usaron $5 \mathrm{mg}$ de $\mathrm{mARN}$ a $200 \mathrm{ng} / \mathrm{mL}$ y $50 \mathrm{mg} / \mathrm{mL}$ del primeradaptador en presencia del buffer de reacción para la síntesis de la primera cadena $(50 \mathrm{mM}$ Tris- $\mathrm{HCl} \mathrm{pH} \mathrm{8,3,} 75 \mathrm{mM} \mathrm{KCl}, 3 \mathrm{mM} \mathrm{MgCl}_{2}$ ) y de $10 \mathrm{mM}$ DTT, $500 \mathrm{mM}$ de cada dNTP y $40 \mathrm{u} / \mathrm{mL}$ de transcriptasa reversa (Marca BRL). La reacción se incubó a $37^{\circ} \mathrm{C}$ por una hora. Para la síntesis de segunda cadena, se adicionó el buffer de reacción (25 mM Tris- $\mathrm{HCl}$ pH 7,5, 100 
$\mathrm{mM} \mathrm{KCl}, 5 \mathrm{mM} \mathrm{MgCl}, 10 \mathrm{mM}\left(\mathrm{NH}_{4}\right)_{2} \mathrm{SO}_{4}, 0,15$ $\mathrm{mM}$ b-NAD ${ }^{+}$), 1,2 mM DTT, $250 \mathrm{mM}$ de tres de los dNTPs, $10 \mathrm{mCi}$ de a ${ }^{32} \mathrm{P}$-dATP, $65 \mathrm{u} / \mathrm{mL}$ de ADN ligasa, $250 \mathrm{u} / \mathrm{mL}$ de ADN polimerasa I y 13 $\mathrm{u} / \mathrm{mL}$ de ARNasa $\mathrm{H}$. La reacción se incubó a $16^{\circ} \mathrm{C}$ por 2 horas, luego se adicionaron $10 \mathrm{u}$ de $\mathrm{T}_{4}$ ADN ligasa y se incubó 5 minutos más a $16^{\circ} \mathrm{C}$. Se hizo extracción fenol/cloroformo y precipitación con $3,5 \mathrm{M}$ de acetato de amonio y 3 volúmenens de etanol absoluto, a temperatura ambiente. EI ADN de doble cadena se recuperó por centrifugación a $14.000 \mathrm{~g}, 20$ minutos a temperatura ambiente y se lavó con $70 \%$ de etanol. Se hizo control electroforético de los tamaños de CADN sintetizados en la primera y segunda cadena, en geles de agarosa al $1 \%$, los cuales fueron visualizados por tinción con bromuro de etidio y por autorradiografía. Para el control electroforético de la síntesis de primera cadena, se hizo una reacción paralela bajo las mismas condiciones de la reacción principal, excepto que se adicionó $1 \mathrm{mCi}$ de a ${ }^{32} \mathrm{P}$-dATP. Para el control electroforético de la síntesis de segunda cadena, se tomó una alícuota de la reacción principal, que había sido marcada con 10 $\mathrm{mCi}$ de a ${ }^{32} \mathrm{P}$-dATP. Después de la síntesis de la segunda cadena, se ligaron los adaptadores que contenían un sitio de restricción para la enzima Sal 1. Para esto, se agregó al ADN recuperado de la segunda síntesis el buffer $\mathrm{T}_{4} \mathrm{ADN}$ ligasa (50 mM Tris- $\mathrm{HCl} \mathrm{pH} \mathrm{7,6,} 10 \mathrm{mM} \mathrm{MgCl}, 1 \mathrm{mM}$ ATP, $1 \mathrm{mM}$ DTT, 5\% (p/v) PEG 8000), $200 \mathrm{mg} /$ $\mathrm{mL}$ de adaptadores Sal I y $200 \mathrm{u} / \mathrm{ml}$ de TADN ligasa. Posteriormente, el cADN de doble cadena, se digirió con Not 1 de tal manera que las moléculas de cADN quedaron con extremos cohesivos diferentes, lo cual permitió obtener clones con insertos direccionados. La reacción de digestión con Not I se llevó a cabo en presencia del buffer de la enzima $(50 \mathrm{mM}$ Tris$\mathrm{HCl} \mathrm{pH} \mathrm{8,0,10} \mathrm{mM} \mathrm{MgCl}, 100 \mathrm{mM} \mathrm{NaCl}$ ) y $1.200 \mathrm{u} / \mathrm{mL}$ de Not I. Se incubó por 2 horas a $37^{\circ} \mathrm{C}$; se hizo extracción fenol/cloroformo y precipitación etanólica. Luego, se hizo un fraccionamiento del cADN por tamaños para eliminar CADN de tamaño pequeño, adaptadores no ligados y fragmentos de primer-adaptador. Para esto, se hizo una cromatografía de filtración por gel, usando una matriz de sephacryl S-500, previamente equilibrada con el buffer de resuspensión del cADN (10mM Tris$\mathrm{HCl} \mathrm{pH}$ 7,5, 0,1 mM EDTA, $25 \mathrm{mM} \mathrm{NaCl})$. La muestra se cargó en la columna y se recolectaron 18 fracciones de elución con el mismo buffer. Se hizo una lectura directa en un contador de centelleo (Liquid scintillation counter, Wallac 1409) de cada fracción y para aquellas que dieron valores por encima de $1 \mathrm{x}$ $10^{4} \mathrm{cpm}$; se calculó la cantidad de cADN.

Los fragmentos de CADN de las fracciones 7 a 12 , se clonaron en el plásmido pSPORT1 previamente cortado con Not1 y Sal 1, con una relación molar vector a inserto de 1:2. En la reacción de ligación, $25 \mathrm{ng}$ de $\mathrm{cDNA}(0,5 \mathrm{ng} / \mathrm{mL})$ se ligaron con $50 \mathrm{ng}$ del vector $(2,5 \mathrm{ng} / \mathrm{mL})$, en presencia del buffer de la T $\mathrm{T}_{4} \mathrm{DNA}$ ligasa $(50 \mathrm{mM}$ Tris $\mathrm{HCl} \mathrm{pH} \mathrm{7,6,} 10 \mathrm{mM} \mathrm{MgCl}, 1 \mathrm{mM}$ ATP, $5 \%$ (p/v) PEG 8000, $1 \mathrm{mM}$ DTT) y $50 \mathrm{u} / \mathrm{mL}$ de $\mathrm{T}_{4} \mathrm{ADN}$ ligasa, en un volumen final de reacción de $20 \mathrm{~mL}$. La reacción se incubó toda la noche a $4^{\circ} \mathrm{C}$. Se prepararon bacterias $\mathrm{DH} 5 \mathrm{a}$ competentes por lavados sucesivos de $500 \mathrm{~mL}$ de cultivo, con agua fría y resuspensión final en $10 \%$ de glicerol. El volumen de la reacción de ligación correspondiente a 2,5 ng de cADN, se introdujo en las bacterias competentes $\left(\sim 3 \times 10^{10}\right.$ células) por electroporación (pulsos de 2,5 KV, $25 \mathrm{mF}$ y 200W, Gen Pulser Bio-Rad 1652076) y finalmente se llevó a $1 \mathrm{~mL}$ con medio SOC $(2 \%$ bacto-triptona, $0,5 \%$ extracto de levadura, 10 $\mathrm{mM} \mathrm{NaCl}, 10 \mathrm{mM} \mathrm{KCl}, 10 \mathrm{mM} \mathrm{MgCl}, 10 \mathrm{mM}$ $\mathrm{MgSO}_{4}, 20 \mathrm{mM}$ glucosa). Se buscó el título de la genoteca sembrando diluciones decimales $\left(10^{-1} \mathrm{a} 10^{-3}\right)$ de la reacción de electroporación diluida en medio SOC en cajas LB-agar con 100 $\mathrm{mg} / \mathrm{mL}$ de ampicilina como marcador de selección de los transformantes. Finalmente, la genoteca se sembró a una densidad de $2 \times 10^{4}$ colonias recombinantes/caja (éste es el número mínimo de clones requeridos para garantizar secuencias de baja abundancia). Posteriormente, se obtuvieron filtros réplica de la caja por transferencia de las colonias a filtros de nitrocelulosa c-extra y crecimiento por 8 horas a $37^{\circ} \mathrm{C}$ en cajas LB-agar-ampicilina, seguido por un crecimiento toda la noche a $37^{\circ} \mathrm{C}$ en cajas LB-agar con $170 \mathrm{mg} / \mathrm{mL}$ de cloranfenicol. 
A partir de cada filtro réplica, se obtuvo un lisado bacteriano resuspendiendo las colonias del filtro en $10 \mathrm{~mL}$ de agua estéril. Esta suspensión se llevó a ebullición por 10 minutos, se centrifugó a $14.000 \mathrm{rpm}$ por 5 minutos y el lisado bacteriano se utilizó para hacer el rastreo por PCR (reacción en cadena de la polimerasa) de los genes de interés.

El rastreo de la genoteca se hizo mediante PCR, utilizando primers específicos de los siguientes genes de copia única: calmodulina, tubulina, actina II, glucosa-fosfato-isomerasa, glucosa-fosfato-deshidrogenasa, miosina y también los ribosomales de copia múltiple, mediante los cuales se pretendía detectar posibles contaminaciones de las preparaciones de mARN con rARN. Los primers fueron diseñados con base en la secuencia reportada para cada uno de los genes. Las secuencias de los primers y los tamaños de los fragmentos amplificados sobre ADN genómico de $P$. falciparum, se muestran en el cuadro 1. La reacción de amplificación se llevó a cabo usando 100 ng de ADN genómico de $P$. falciparum, o $1 \mathrm{~mL}$ de los $10 \mathrm{~mL}$ de lisado bacteriano como ADN plantilla, 35 pmoles de cada primer, $250 \mathrm{mM}$ de cada dNTP, $4 \mathrm{mM} \mathrm{MgCl}$, 2,5 u de Taq polimerasa y el buffer de la reacción $(10 \mathrm{mM}$ Tris $\mathrm{HCl} \mathrm{pH} 9,0$, $50 \mathrm{mM} \mathrm{KCl}, 0,1 \%$ Triton $\mathrm{X}-100)$. Las condiciones de la reacción de PCR fueron las siguientes: 1 ciclo de $95^{\circ} \mathrm{C}$ por 5 minutos y $72^{\circ} \mathrm{C}$ por 5 minutos con adición de la enzima. 40 ciclos de $94^{\circ} \mathrm{C}$ por 2 minutos, temperatura de anillaje por 2 minutos y $72^{\circ} \mathrm{C}$ por dos minutos. Un ciclo final de $72^{\circ} \mathrm{C}$ por 5 minutos. La temperatura de anillaje para los genes de actina II, glucosa-fosfato-isomerasa y ribosomales fue de $55^{\circ} \mathrm{C}$ y para los genes de calmodulina, tubulina, glucosa-fosfato-deshidrogenasa y miosina fue de $53^{\circ} \mathrm{C}$.

\section{Resultados y discusión}

\section{Extracción de ARN total}

Para extraer ARN total, se usaron parásitos en estadio de trofozoitos maduros (más de 36 horas), en los cuales se dan las mayores tasas de síntesis de ARN (18). La extracción se realiza con detergentes no iónicos como el sarkosilato, que lisan la membrana plasmática y en presencia de isotiocianato de guanidina y bmercaptoetanol que denaturan las proteínas e inactivan las ARNasas (7).

La mezcla de ácidos nucleicos obtenida después de extracción orgánica de proteínas, se separa por sedimentación sobre un colchón de cloruro de cesio, en el cual el ARN se separa del ADN y proteínas debido a la mayor densidad que adquiere al unir cesio.

Los resultados obtenidos en las preparaciones de ARN total (cuadro 2) muestran una relación de absorbancias $A_{260} / A_{280}$ muy cercanas al valor de 2,3, característico del ARN de P. falciparum. La composición de bases del genoma del parásito $\left(70-90 \%\right.$ de A-T) implica valores altos ${ }^{3}$ 2.3) dado el mayor coeficiente de extinción de estas bases (19).

Los rendimientos obtenidos oscilan entre 400 y $1.700 \mathrm{mg}$ de ARN a partir de 4-8,6 x $10^{9}$ parásitos. Estos valores son similares a los obtenidos anteriormente en el Laboratorio de Bioquímica, los cuales oscilan entre 450 y $700 \mathrm{mg}$ a partir de $2 \times 10^{9}$ parásitos, en los mismos estadios de desarrollo (19).

Cuadro 1. Secuencias de los primers diseñados para cada gen y tamaños de los fragmentos amplificados sobre ADN genómico de $P$. falciparum.

\begin{tabular}{|c|c|c|c|c|}
\hline Gen & $\begin{array}{c}\text { Secuencia del primer } \\
\text { sentido }\end{array}$ & $\begin{array}{c}\text { Secuencia del primer } \\
\text { antisentido }\end{array}$ & $\begin{array}{c}\text { Longitud } \\
\text { fragmento } \\
\text { amplificado }(\mathrm{pb})\end{array}$ & Ref. \\
\hline Calmodulina & GGGTATCATCATTITAACAAAC & GCCTTCCGAGTIIITGATAGAGATGG & 190 & 11 \\
\hline Miosina & TCCTCCTTCTGGTTCAATTCTTG & CGTATTCAGACAGCAATAATGGC & 725 & 12 \\
\hline Tubulina & GAATTCTTAGAGTGGTACCTATTGTGG & GGATCCGTITAACATTTGTTCGTCAAC & 915 & 13 \\
\hline Actina II & GAATTCATGTCTGAAGAAGCTGTTGCT & GGATCCCATGGCTATGTAACATAGTTT & 1.043 & 14 \\
\hline GPI & GAATTCGCTTTAAGAATACCCATAGAGA & GGATCCCGACAATTCTACTTTCATATAA & 1.284 & 15 \\
\hline GPDH & GAATTCAGCAATATTAGGTATGGGTAG & GGATCCGGAGGTAATGCTAAATATAAC & 1.115 & 16 \\
\hline Ribosomal & GTAACTATTCTAGGGGAACTA & AGAAATAGAGTAAAAAACAATITA & 918 & 17 \\
\hline
\end{tabular}


Cuadro 2. Cultivo de parásitos y extracción de ARN total.

\begin{tabular}{cccc}
\hline Experimento n parásitos & $\begin{array}{c}\text { ARN obtenido } \\
\text { (mg) } / 10^{9}\end{array}$ parásitos & $\begin{array}{c}\text { Relación } \\
\mathbf{A}_{260230}\end{array}$ \\
\hline 1 & $8,52 \times 10^{9}$ & 1.380 & 2,26 \\
2 & $8,30 \times 10^{9}$ & 1.331 & 2,23 \\
3 & $5,42 \times 10^{9}$ & 1.730 & 2,23 \\
4 & $9,50 \times 10^{9}$ & 1.210 & 2,20 \\
5 & $4,00 \times 10^{9}$ & 397,6 & 2,25 \\
6 & $6,33 \times 10^{9}$ & 1.372 & 2,26 \\
7 & $8,60 \times 10^{9}$ & 1.727 & 2,27 \\
\hline
\end{tabular}

Volumen de cultivo por experimento: $200 \mathrm{~mL}$.

Las variaciones encontradas en los rendimientos obtenidos en los diferentes experimentos, posiblemente puedan ser debidas a diferencias en el estado de madurez de la población de parásitos, puesto que éstos eran tomados para la extracción, en un estado asincrónico. La precipitación etanólica que se hace en la parte final del proceso, también puede contribuir a las variaciones en el rendimiento del ARN extraido.

\section{Separación de mARN por cromatografía de afinidad}

Un aspecto crítico en cromatografía de afinidad es que la capacidad de la columna esté acorde con la cantidad de ARN que va a ser seleccionado. Para este trabajo, se utilizó una columna comercial (Marca BRL) con una capacidad de 6 unidades de $A_{260}$ /columna (100 mg de oligo dT celulosa), lo cual significa que puede unir aproximadamente $200 \mathrm{mg}$ de mARN. Por tanto, si el mARN constituye de 2 a $5 \%$ del total de la célula, la cantidad de ARN total con la cual se podría cargar la columna oscila entre 4 y $10 \mathrm{mg}$.
Usualmente, en una cromatografía de afinidad, se recupera entre 1 y $2 \%$ del ARN total como mensajero (5). Los rendimientos obtenidos en cada uno de los experimentos (cuadro 3) están dentro del rango de lo esperado, a pesar de la pérdida que ocurre después de una precipitación etanólica que es, aproximadamente, $20 \%$ del material.

La matriz de la columna forma complejos oligo dT: poli $\mathrm{A}^{+}$en presencia de buffer de alta fuerza iónica y la elución del mensajero se hace con buffer de baja fuerza iónica, lo cual desestabiliza los pares de bases híbridos. En los dos experimentos realizados para la separación de mARN, se obtuvo un mayor rendimiento en el segundo, a pesar de haber cargado la columna con una menor cantidad de ARN total. Dado que en este experimento hubo problemas en el flujo de la columna, fue necesario hacer la elución del mARN con buffer precalentado a $70^{\circ} \mathrm{C}$. A pesar de que la elución no requiere altas temperaturas o agentes desnaturalizantes, se sugiere que esta temperatura de elución, favoreció la separación de las cadenas de ARN poli $\mathrm{A}^{+}$del oligo dT de la matriz.

Por otra parte, la relación de absorbancias $\mathrm{A}_{260} / \mathrm{A}_{280}$ demuestra valores muy cercanos al valor esperado de 2,3 para $P$. falciparum, lo cual permite concluir de modo indirecto que las preparaciones obtenidas de mARN presentan una buena calidad y pureza; de acuerdo con estudios previos de este laboratorio, las preparaciones de ARN obtenidas mediante colchones de cloruro de cesio se han determinado como libres de ADN por lecturas fluorométricas (19).

Cuadro 3. Rendimiento de mARN obtenido por cada método.

\begin{tabular}{lccccc}
\hline Método & Experimento & ARN total $(\mathbf{m g})$ & mARN $(\mathbf{m g})$ & ${\text { Rendimiento }(\%)^{\mathbf{3}}}$ & Relación $^{\mathbf{A}_{260 / 280}}$ \\
\hline $\begin{array}{l}\text { Cromatografía de } \\
\text { afinidad en }\end{array}$ & 1 & 4,069 & 33,3 & 0,8 & 2,26 \\
$\begin{array}{l}\text { columnas de oligo } \\
\text { dT celulosa }\end{array}$ & 2 & 2,603 & 37,2 & 1,4 & 2,20 \\
$\begin{array}{l}\text { Captura de mRNA } \\
\text { en solución }\end{array}$ & 1 & & & & 2,34 \\
\hline
\end{tabular}

${ }^{3}$ El rendimiento del mARN se obtuvo así: ug mARN/ug ARN total $\times 100$. 
Con los resultados obtenidos, se mostró que con la cromatografía de afinidad se separaron mensajeros en un rango de tamaño (entre 0,4 y $4 \mathrm{~kb})$ que permitiría la expresión de proteínas entre 15 y $220 \mathrm{kDa}$, lo cual estaría cubriendo un espectro relativamente amplio en cuanto a tamaños se refiere de las proteínas del parásito.

\section{Separación de mARN con el sistema de captura de mARN en solución}

Este sistema usa un primer (iniciador) oligo dT biotinilado para hibridizar en solución a la región 3' poli $\mathrm{A}^{+}$presente en el mARN y los híbridos se capturan usando estreptavidina acoplada a partículas magnéticas. Este proceso produce una fracción pura de mARN maduro después de sólo una ronda de separación magnética (6).

Mediante este sistema, se obtuvieron rendimientos comparables a los obtenidos por cromatografía de afinidad (cuadro 3), pero con relaciones ópticas mayores, lo cual puede ser un indicativo de mayor pureza. Entre más pura sea la preparación, el valor obtenido para la relación de absorbancias $A_{260} / A_{280}$, debe acercarse al calculado para plasmodio. De acuerdo con la literatura (6), con este sistema se pueden separar mensajeros intactos, lo cual se pone de manifiesto en el rango de tamaños obtenidos para el CADN.

\section{Evaluación de la representatividad de la población de mensajeros}

\section{Síntesis de $C A D N$}

Para el caso de plasmodio, se ha informado una población de mensajeros que se extiende desde aproximadamente 0,5 a $8 \mathrm{~kb}$, rango que corresponde a una población de proteínas desde 15 a 270 kD (19). Previamente se han obtenido preparaciones de mARN del parásito por cromatografía de afinidad en oligo dT celulosa y los ensayos de traducción in vitro han demostrado productos en un rango de 20 a 200 kD (19).

La calidad del mARN determina la cantidad máxima de secuencias que pueden ser convertidas a cADN. De esta manera, el análisis del tamaño de la población de cADN sintetizado (que en gran parte depende de la calidad del mARN) permite evaluar indirectamente la calidad de dicho ARN. Es importante destacar que la transcriptasa reversa usada para la síntesis de cADN de primera cadena, no contiene actividad ARNasa $\mathrm{H}$, lo cual elimina la actividad de hidrólisis del ARN antes de iniciar la síntesis de cADN y del híbrido en el proceso de transcripción, produciendo una población de cADN representativa de la población de mARN y un cADN de longitud completa.

En la figura 1, parte A, carril 1, se muestra el rango de tamaños del CADN sintetizado a partir de mARN de $P$. falciparum obtenidos por el método de cromatografía de afinidad $(0,4-4 \mathrm{~Kb})$ y en la parte $B$, carril 1 , el rango de tamaños de los CADN sintetizados a partir de mensajeros obtenidos por el método de captura de mARN en solución $(0,4-8 \mathrm{~Kb})$.

Al comparar los resultados obtenidos en cuanto a rango de tamaño de cADN sintetizado a partir de preparaciones de mARN obtenidas por los dos métodos (cuadro 4 y figura 1), se observa que con el sistema de captura de mensajero en solución, fue posible obtener longitudes mayores en la síntesis del cADN. Posiblemente, la menor manipulación de las muestras, al eliminar los pasos sucesivos a través de las columnas de afinidad, aumentan la posibilidad de mantener los mensajeros más intactos. El experimento 2 (cuadro 4) de síntesis de cADN de mARN obtenido por cromatografía de afinidad es un ejemplo de esta posibilidad, ya que en este caso hubo problemas de elución en la columna.

Cuadro 4. Tamaño cADN de primera cadena obtenido por cada método.

\begin{tabular}{lcc}
\hline Método & Experimento & $\begin{array}{c}\text { Rango de tamaño } \\
\text { obtenido (Kb) }\end{array}$ \\
\hline $\begin{array}{l}\text { Oligo dT } \\
\text { celulosa }\end{array}$ & 1 & $0,4-4$ \\
$\begin{array}{l}\text { Oligo dT } \\
\text { celulosa }\end{array}$ & 2 & $0,5-2,5$ \\
$\begin{array}{l}\text { Captura de } \\
\text { mARN en } \\
\text { solución }\end{array}$ & 1 & $0,4-8$ \\
\hline
\end{tabular}


A

M

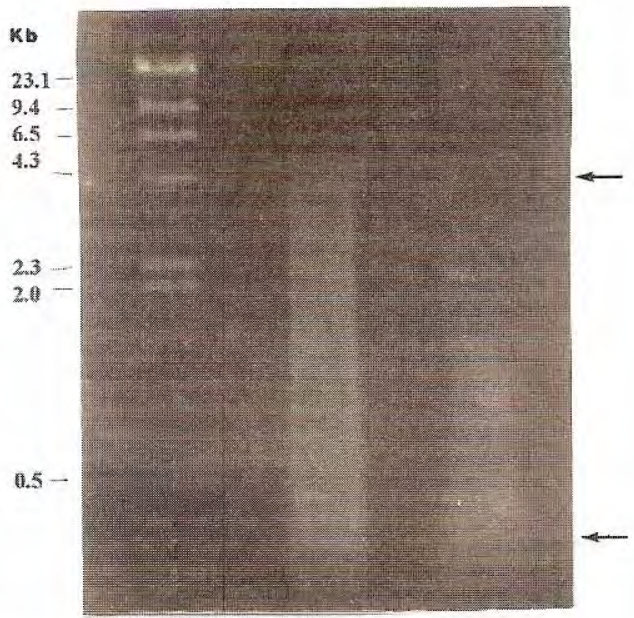

B

M 12

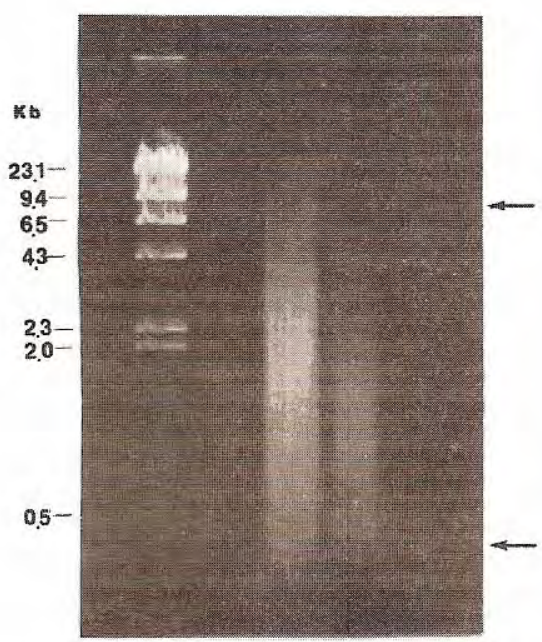

Figura 1. Tamaño del CADN de primera y segunda cadena sintetizado a partir de mARN de $P$. falciparum obtenidos por el método de cromatografía de afinidad (A) y por el método de captura en solución (B).

Las muestras de cADN se sometieron a electroforesis en un gel de agarosa al 1\%; se corrieron a $100 \mathrm{~V}$ durante una hora y se tiñeron con bromuro de etidio.

A M. marcador de tamaño molecular lambda Hind III. 1: CADN de primera cadena 2: cADN de segunda cadena. B M: marcador de tamaño molecular lambda Hind III. 1: CADN de primera cadena 2: cADN de segunda cadena.

\section{Búsqueda de la representatividad en genotecas de CADN}

Se obtuvieron resultados de una genoteca de cADN construida a partir del mRNA obtenido del primer experimento de separación por cromatografía de afinidad. Analizando sólo un $10 \%$ del total de la genoteca, se encontraron 5 de los 7 genes rastreados: tubulina, actina II, calmodulina, glucosa-fosfato-isomerasa y ribosomal, a partir de $2 \times 10^{4}$ colonias recombinantes (cuadro 5). La figura 2 muestra

Cuadro 5. Representatividad de la población de mensajeros en genotecas de CADN.

\begin{tabular}{lcc}
\hline Método & Genes rastreados & Presencia \\
\hline & Miosina & - \\
& Tubulina & + \\
Cromatografía de & Calmodulina & + \\
afinidad en columna & Actina & + \\
oligo dT celulosa & GPI & + \\
& GPDH & - \\
& Ribosomales & + \\
\hline
\end{tabular}

los productos de amplificación para cada uno de los genes sobre el ADN genómico de $P$. falciparum y sobre el lisado bacteriano obtenido al sembrar el $10 \%$ de la genoteca. Para cada gen se obtuvo un producto de amplificación del tamaño esperado; sin embargo, en el caso del gen de actina II, los primers fueron diseñados de tal modo que el producto de amplificación incluye un intrón; por este motivo, cuando los primers amplifican sobre el CADN de la genoteca, se obtiene un producto de amplificación de menor tamaño que no incluye el intrón.

Estos resultados permiten concluir que mediante el sistema de cromatografía de afinidad en columnas de oligo dT celulosa, se obtiene una población de mensajeros que, aunque contaminada con rARN, como lo mostró el hallazgo de clones con genes ribosomales, es representativa del genoma del parásito, a juzgar por la presencia de genes de copia única, cuya abundancia es menor de $0,1 \%$. La 


\section{A}

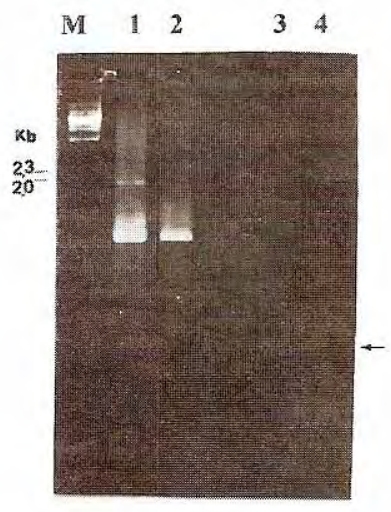

C

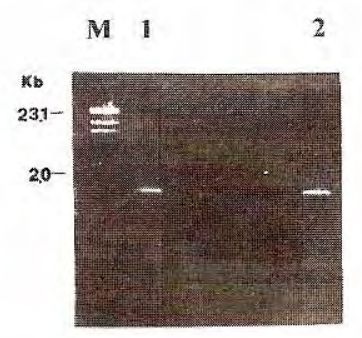

B

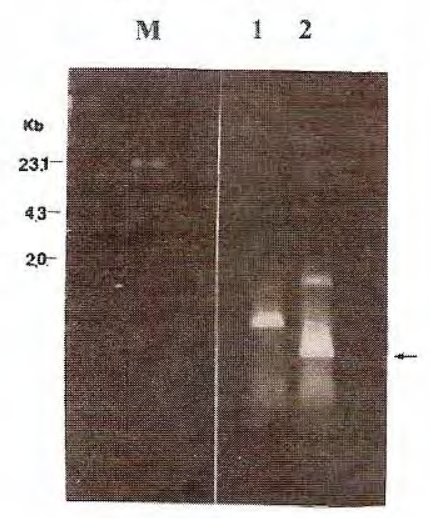

D

Figura 2. Rastreo por PCR de la genoteca de cADN.

Se construyó una genoteca de cADN a partir de mARN obtenido por cromatografía de afinidad y se sembró una densidad de $2 \times 10^{4}$ colonias recombinantes/caja. Se obtuvo un lisado bacteriano de $10 \mathrm{~mL}$, del cual se tomó una alícuota de un microlitro y se sometió a amplificación por PCR, de acuerdo con el protocolo descrito en materiales y métodos.

A. M: marcador de tamaño molecular lambda Hind III. 1: amplificado sobre ADN de P. falciparum usando primers para el gen de tubulina. 2: amplificado sobre el lisado de la genoteca usando primers para el gen de tubulina. 3: producto de amplificación sobre ADN de P. falciparum usando primers para el gen de calmodulina. 4: producto de amplificación sobre el lisado de la genoteca usando primers para el gen de calmodulina.

B. M: marcador de tamaño molecular lambda Hind III. 1: amplificado sobre ADN de $P$. falciparum usando primers para el gen de actina. 2: amplificado sobre el lisado de la genoteca usando primers para el gen de actina.

C. M: marcador de tamaño molecular lambda Hind III. 1: producto de amplificación sobre ADN de P. falciparum usando primers para el gen de giucosa-fosíato-isomerasa. 2: producto de amplificación sobre el lisado de la genoteca usando primers para el gen de glucosa-fosfato-isomerasa.

D. M: marcador de tamaño molecular lambda Hind III. 1: producto de amplificación sobre ADN de P. falciparum usando primers para el gen de ARN ribosomal. 2: producto de amplificación sobre el lisado de la genoteca usando primers para el gen de ARN ribosomal. 
contaminación con rARN en las genotecas de cADN es un hecho corriente, debido a la dificultad de eliminarlo de las preparaciones de mensajero. En el caso de plasmodio, el primer oligo dT utilizado para separar los mensajeros, puede haberse unido adicionalmente a los innumerables segmentos ricos en adenina, que posee su genoma.

Debido a que sólo se rastreó el $10 \%$ de la genoteca, no fue posible evidenciar la presencia de genes como GPDH y miosina. La ausencia de miosina puede deberse al gran tamaño del gen que lo hace seguramente mucho más escaso en el preparado.

Las muestras de cADN se sometieron a electroforesis en un gel de agarosa al $1 \%$, se corrieron a $100 \mathrm{~V}$ durante 1 hora y se tiñeron con bromuro de etidio.

\section{Referencias}

1. Aviv $\mathbf{H}$, Leder P. Purification of biologically active globin messenger RNA by chromatography on oligothymidylic acid-cellulose. Proc Nat Acad Sci USA 1972;69(6):1408-12.

2. Williamson R. Genetic engineering 1. Academic Press; 1981:2-55.

3. Darnell JE, Philipson L, Wall R, Adesnik M. Polyadenylic acid sequences: role in conversion of nuclear RNA into messenger RNA. Science 174: 507510.

4. Moore CL, Sharp PA. Site-specific polyadenylation in a cell-free reaction. Cell 1984;36:581-91.

5. Kingston RE. Preparation and analysis of RNA. Preparation of poly (A)+ RNA. In: Ausubel FM, Brent R, Kingston RE, Moore DD, Seidman JG, Smith AJ, Strhl $\mathrm{K}$, editors. Current protocols in molecular biology. Boston: Massachusetts General Hospital and Harvard Medical School; 1994:4.5.2-3.

6. PROMEGA. PolyATtract mRNA isolation systems. Technical manual No. TM021. Casa comercial PROMEGA; 1995.

7. Rojas MO, Wasserman M. Stage-specific expression of the calmodulin gene in Plasmodium falciparum. J Biochem 1995; 118:1118-23.
8. Goman M, Langstey G, Hyde JE, Yankovsky NK, Zolg JW, Scaife JG. The establishment of genomic DNA libraries for human malaria parasite Plasmodium falciparum and identification of individual clones by hybridisation. Mol Biochem Parasitol 1982;5:391.

9. González R. Construcción de una genoteca de cDNA de Plasmodium falciparum y búsqueda posterior del gen de calmodulina (tesis). Santa Fe de Bogotá: Universidad Nacional de Colombia, Departamento de Química; 1995.

10. Gubbler U, Hoffman BJ. A simple and very efficient method for generating cDNA libraries. Gene 1983;25: 263.

11. Robson $\mathbf{K J H}$, Jennings $\mathbf{M W}$. The structure of the calmodulin gene of Plasmodium falciparum. Mol Biochem Parasitol 1991;46:19-34.

12. Forero C. Proteínas de unión a actina en Plasmodium falciparum (tesis). Santa Fe de Bogotá: Universidad Nacional de Colombia, Departamento de Química; 1996.

13. Delves CJ, Ridely RG, Goman M, Holloway SP, Hyde JE, Scaife J. Cloning of beta-tubulin gene from Plasmodium falciparum. Mol Microbiol 1989;3:1511-19.

14. Wesseling G, Sinijders PJF, van Someren $P$, Jansen J, Smits MA, Schoenmakers JGG. Stage-specific expression and genomic organization of the actin genes of the malaria parasite Plasmodium falciparum. Mol Biochem Parasitol 1989; 35:167-76.

15. Kaslow DC, Hill S. Cloning metabolic pathway genes by complementation in Escherichia coli: isolation and expression of Plasmodium falciparum glucose phosphate isomerase. J Biol Chem 1990;265:12337-41.

16. O'Brien E, Kurdi-Haidar B, Wanachiwanawin W, Carvajal JL, Vulliamy TJ, Cappadoro M, Mason PJ, Luzzatto L. Cloning of the glucose-6-phosphate dehydrogenase gene from Plasmodium falciparum. Mol Biochem Parasitol 1994;64:313-26.

17. McCutchan TF, De La Cruz VF, Lal AA, Gunderson JH, Elwood HJ, Sogin ML. Primary sequences of two small subunit ribosomal RNA genes from Plasmodium falciparum. Mol Biochem Parasitol 1988;28:63-8.

18. Rojas MO, Wasserman M. Temporal relationships on macromolecular synthesis during the asexual cell cycle of Plasmodium falciparum. Trans R Soc Trop Med Hyg 1985;79:792-6.

19. Rojas MO. Expresión específica de estado del gen de calmodulina en Plasmodium falciparum (tesis). Santa Fe de Bogotá: Universidad Nacional de Colombia, Departamento de Química; 1995. 